Research Article

\title{
Karyotype differentiation of four Cestrum species (Solanaceae) revealed by fluorescent chromosome banding and FISH
}

\author{
Thiago Fernandes, Letícia do Nascimento Andrade de Almeida Rego, Mariana Nardy, \\ Priscila Mary Yuyama and André Luís Laforga Vanzela \\ Laboratório de Biodiversidade e Restauração de Ecossistemas, Centro de Ciências Biológicas, \\ Universidade Estadual de Londrina, Londrina, PR, Brazil.
}

\begin{abstract}
The karyotypes of four South American species of Cestrum (C. capsulare, C. corymbosum, C. laevigatum and C. megalophylum) were studied using conventional staining, C-CMA/DAPI chromosome banding and FISH with 45S and $5 S$ rDNA probes. The karyotypes showed a chromosome number of $2 n=2 x=16$, with metacentric chromosomes, except for the eighth submeta- to acrocentric pair. Several types of heterochromatin were detected, which varied in size, number, distribution and base composition. The $\mathrm{C}^{-\mathrm{CMA}^{+}}$bands and $45 \mathrm{~S}$ rDNA were located predominantly in terminal regions. The $\mathrm{C}-\mathrm{CMA}^{+} / \mathrm{DAPI}^{+}$bands appeared in interstitial and terminal regions, and the C-DAPI bands were found in all chromosome regions. The 5 S rDNA sites were observed on the long arm of pair 8 in all species except $C$. capsulare, where they were found in the paracentromeric region of the long arm of pair 4 . The differences in band patterns among the species studied here, along with data from other nine species reported in the literature, suggest that the bands are dispersed in an equilocal and non-equilocal manner and that structural rearrangements can be responsible for internal karyotype diversification. However, it is important to point out that the structural changes involving repetitive segments did not culminate in substantial changes in the general karyotype structure concerning chromosome size and morphology.
\end{abstract}

Key words: Cestrum, chromosome banding, FISH, heterochromatin, physical maps, 45S and 5S rDNA.

Received: May 2, 2008; Accepted: September 8, 2008.

\section{Introduction}

The genera Cestrum L., Sessea Ruiz \& Pav. and Vestia Willd. belong to the tribe Cestreae. Their representatives are trees, subtrees or bushes that are distributed in tropical and subtropical America (Hunziker, 1979). The few Cestrum species that have been cytogenetically studied presented the largest chromosomes of the family, up to about $14 \mu \mathrm{m}$ long (Fregonezi et al., 2006; Las Peñas et al., 2006). Cestrum is the largest genus of the tribe (Judd et al., 1999), with 50 species in Brazil (Hunziker, 2001). Chromosome banding studies have shown that in Cestrum heterochromatin varies in amount and type, and that the similarity observed among karyotypes regarding chromosome size and morphology is apparent (see Berg and Greilhuber, 1992, 1993a, 1993b; Fregonezi et al., 2006). In spite of the small number of species studied, significant information about the occurrence and distribution of different classes of repetitive DNA (45S and 5S rDNA, micro-

Send correspondence to André Luís Laforga Vanzela. Laboratório de Biodiversidade e Restauração de Ecossistemas, Centro de Ciências Biológicas, Universidade Estadual de Londrina, Caixa Postal 6001, 86051-990 Londrina, PR, Brazil. E-mail: andrevanzela@uel.br. satellites and retroelements) has been reported (Berg and Greilhuber, 1992, 1993a, 1993b; Fregonezi et al., 2006, 2007; Las Peñas et al., 2006). Sykorová et al. (2003a, 2003b) described the absence of Arabidopsis (DC.) Heynh.-type (TTTAGGG) telomeres, which seem to be replaced by an A/T-rich minisatellite family in Cestrum, Sessea and Vestia, besides an uncommon occurrence of $45 \mathrm{~S}$ and $5 \mathrm{~S}$ rDNA in B-chromosomes of Cestrum parqui L'Her. In two other studies, Fregonezi et al. (2006, 2007) described different numbers of $45 \mathrm{~S}$ rDNA sites and the constancy in number and location of 5S rDNA sites in four species of Cestrum, plus the occurrence of a Ty3-gypsy retrotransposon family dispersed along chromosomes and forming blocks associated with NORs in C. intermedium Sendtn. and C. strigilatum Ruiz \& Pav.

The aim of this study was to extend the information about the occurrence and the physical location of some repetitive DNAs in four South American Cestrum species. This work involved conventional karyotype determination and the physical location of different heterochromatin families, as well as the 45S and 5S rDNA sites. Such information is useful in evolutionary studies of this group and allows the development of new directions in the elucidation of karyotype differentiation in Cestrum. 


\section{Materials and Methods}

Seeds of four Cestrum species were collected in five different localities, always from three individuals of each population, which included (i) C. capsulare Carvalho \& Schnoor from Curiúva and Ventania, Paraná State, Brazil (24 03'14" S, 50²7'23' W), (ii) C. corymbosum Schltdl. from Tibagi, Paraná State, Brazil (24 $38^{\prime}$ 44” S, 50 34' 11 " W), (iii) C. laevigatum Schltdl. from Misiones, Argentina $\left(26^{\circ} 48^{\prime} 25^{\prime \prime} \mathrm{S}, 54^{\circ} 44^{\prime} 22^{\prime \prime} \mathrm{W}\right)$, and (iv) $C$. megalophylum Dunal from Salvador, Bahia State, Brazil $\left(12^{\circ} 52^{\prime} 51^{\prime \prime} \mathrm{S}, 38^{\circ} 21^{\prime} 41^{\prime \prime} \mathrm{W}\right)$. Seeds were germinated and the seedlings were cultivated in the Laboratory of Biodiversity and Restoration of Ecosystems (LABRE) at the State University of Londrina (UEL). Vouchers are kept at the FUEL herbarium. For cytogenetic analysis, slides were prepared from root tips pretreated with $0.05 \%$ colchicine for $4 \mathrm{~h}$, fixed in Farmer solution (ethanol/acetic acid 3:1, v:v) for up to $24 \mathrm{~h}$, and stored at $-20{ }^{\circ} \mathrm{C}$. Roots were hydrolyzed in $1 \mathrm{M} \mathrm{HCl}$ for $10 \mathrm{~min}$ at $60{ }^{\circ} \mathrm{C}$, dissected in a drop of $45 \%$ acetic acid and coverslipped. Coverslips were removed in liquid nitrogen, and the preparations were stained with 2\% Giemsa and permanently mounted in Entellan (Merck). Chromosome measurements were made based on five metaphases, using the MicroMeasure 3.3 software (http://www.biology.colostate.edu), and the values of total length, arm ratio and relative size were considered for idiogram construction. Chromosomes were classified according to Guerra (1986).

Chromosome banding was performed as described by Schwarzacher et al. (1980), with minor modifications. Root tips were digested in an enzyme solution composed of $4 \%$ cellulase (w/v) and $40 \%$ pectinase $(\mathrm{v} / \mathrm{v})$ at $37{ }^{\circ} \mathrm{C}$ and dissected in a drop of $45 \%$ acetic acid. The slides were aged for three days and incubated in $45 \%$ acetic acid for $10 \mathrm{~min}$ at $60{ }^{\circ} \mathrm{C}$, in $5 \%$ barium hydroxide for $10 \mathrm{~min}$ at room temperature, and in $2 \mathrm{xSSC}, \mathrm{pH} 7.0$, for $10 \mathrm{~min}$ at $60{ }^{\circ} \mathrm{C}$. The samples were then washed in distilled water, air dried and stained with fluorochromes: $0.5 \mathrm{mg} / \mathrm{mL}$ chromomycin A3 (CMA) for $1.5 \mathrm{~h}$, and $2 \mu \mathrm{g} / \mathrm{mL}$ 4-6-diamidino-2phenylindole (DAPI) for $30 \mathrm{~min}$. Slides were mounted with a medium composed of glycerol/McIlvaine buffer $(\mathrm{pH} 7.0)$ 1:1, plus $2.5 \mathrm{mM} \mathrm{MgCl}_{2}$. The option for CMA/DAPI staining after chromosome banding was to improve the contrast of the fine bands, due to greater retreat of the euchromatin and preservation of the heterochromatin.

Fluorescent in situ hybridization (FISH) was performed according to the procedures described by HeslopHarrison et al. (1991) and Cuadrado and Jouve (1994), with minor modifications. Slides were prepared as described for chromosome banding and immediately used for FISH. A wheat p Ta71 probe containing the $45 \mathrm{~S}$ rDNA sequence (Gerlach and Bedbrook, 1979) was labeled with digoxigenin-11-dUTP by nick translation, and a pTa794 probe containing the 5S rDNA sequence (Gerlach and Dyer,
1980) was labeled with biotin-14-dATP, also by nick translation. For each slide $34 \mu \mathrm{L}$ of a denatured hybridization mixture was applied. This mixture was composed for $100 \mathrm{ng}$ of labeled probe ( $4 \mu \mathrm{L}$ of each probe), $10 \quad 0 \%$ formamide $(15 \mu \mathrm{L}), 50 \%$ polyethylene glycol $(6 \mu \mathrm{L})$, 20xSSC $(3 \mu \mathrm{L}), 100 \mathrm{ng}$ of calf thymus DNA $(1 \mu \mathrm{L})$, and $10 \% \operatorname{SDS}(1 \mu \mathrm{L})$. Both slide and mixture were denatured at $90{ }^{\circ} \mathrm{C}$ for $10 \mathrm{~min}$, and hybridization was performed overnight at $37^{\circ} \mathrm{C}$ in a humidified chamber. Post-hybridization washes were carried out in $2 \mathrm{xSSC}, 20 \%$ formamide in $0.1 \mathrm{xSSC}, 0.1 \mathrm{xSSC}$ and $4 \mathrm{xSSC} / 0.2 \%$ Tween 20 , all at $42{ }^{\circ} \mathrm{C}$. The probes were simultaneously detected with a solution composed of 5\% BSA, avidin-FITC conjugate and antidigoxigenin-rhodamine conjugate (100:1:1, v:v:v), followed by post-detection baths in $4 \times \mathrm{SSC} / 0.2 \%$ Tween 20 at room temperature. Slides were mounted in $25 \mu \mathrm{L}$ of a medium composed of $23 \mu \mathrm{L}$ of DABCO solution [1,4-diazabicyclo (2.2.2)-octane (2.3\%), $20 \mathrm{mM}$ Tris $\mathrm{HCl}, \mathrm{pH} 8.0$, $(2 \%)$ and glycerol $(90 \%)$, in distilled water], $1 \mu \mathrm{L}$ of $2 \mu \mathrm{g} / \mathrm{mL}$ DAPI, and $1 \mu \mathrm{L}$ of $50 \mathrm{mM} \mathrm{MgCl}_{2}$.

All the images were acquired with a Leica DM 4500 $\mathrm{B}$ microscope equipped with a DFC 300FX camera and the Leica IM50 4.0 software, and optimized for best constrast and brightness with iGrafx Image software.

\section{Results}

Conventional karyotype analysis of the four Cestrum species showed a constant chromosome number of $2 n=2 x$ $=16$ with metacentric chromosomes, except for the smallest pair that was from submetacentric to acrocentric (Figures 1A, B, C and D and Figure 4). The interphase nuclei were also always of the reticulate type, without evident chromocenters when the nuclei were more condensed (Figure 1A) and with some chromocenters when the nuclei were decondensed (Figure 1B). Differences were found in the karyotype formulae and haploid set sizes, being $7 \mathrm{~m}+$ $1 \mathrm{sm}$ and $24 \mu \mathrm{m}$ in Cestrum capsulare (Figures 1A and 4A), $7 \mathrm{~m}+1 \mathrm{a}$ in C. corymbosum, and $7 \mathrm{~m}+1 \mathrm{sm}$ in $C$. laevigatum, but both species presented $28 \mu \mathrm{m}$ of haploid set sizes (Figures $1 \mathrm{~B}$ and $4 \mathrm{~B}$ and Figures $1 \mathrm{C}$ and $4 \mathrm{C}$, respectively). An atypical idiogram was obtained for $C$. megalophylum, due to the presence of the heteromorphic pair 1 (Figures 1D and 4D), but the karyotype formula was $7 \mathrm{~m}+1 \mathrm{a}$. The results of the chromosome measurements showed that $C$. megalophylum has the largest and $C$. capsulare the smallest haploid set size, while $C$. corymbosum and C. laevigatum showed similar karyotype length.

CMA/DAPI staining after treatment with acetic acid, barium hydroxide and 2xSSC was useful to reveal $\mathrm{CMA}^{+} / \mathrm{DAPI}^{-}, \mathrm{CMA}^{-} / \mathrm{DAPI}^{+}$and $\mathrm{CMA}^{+} / \mathrm{DAPI}^{+}$bands (Figure 2). Chromosome banding demonstrated quantitative and qualitative variation among the four species studied. The larger heterochromatic blocks were located 

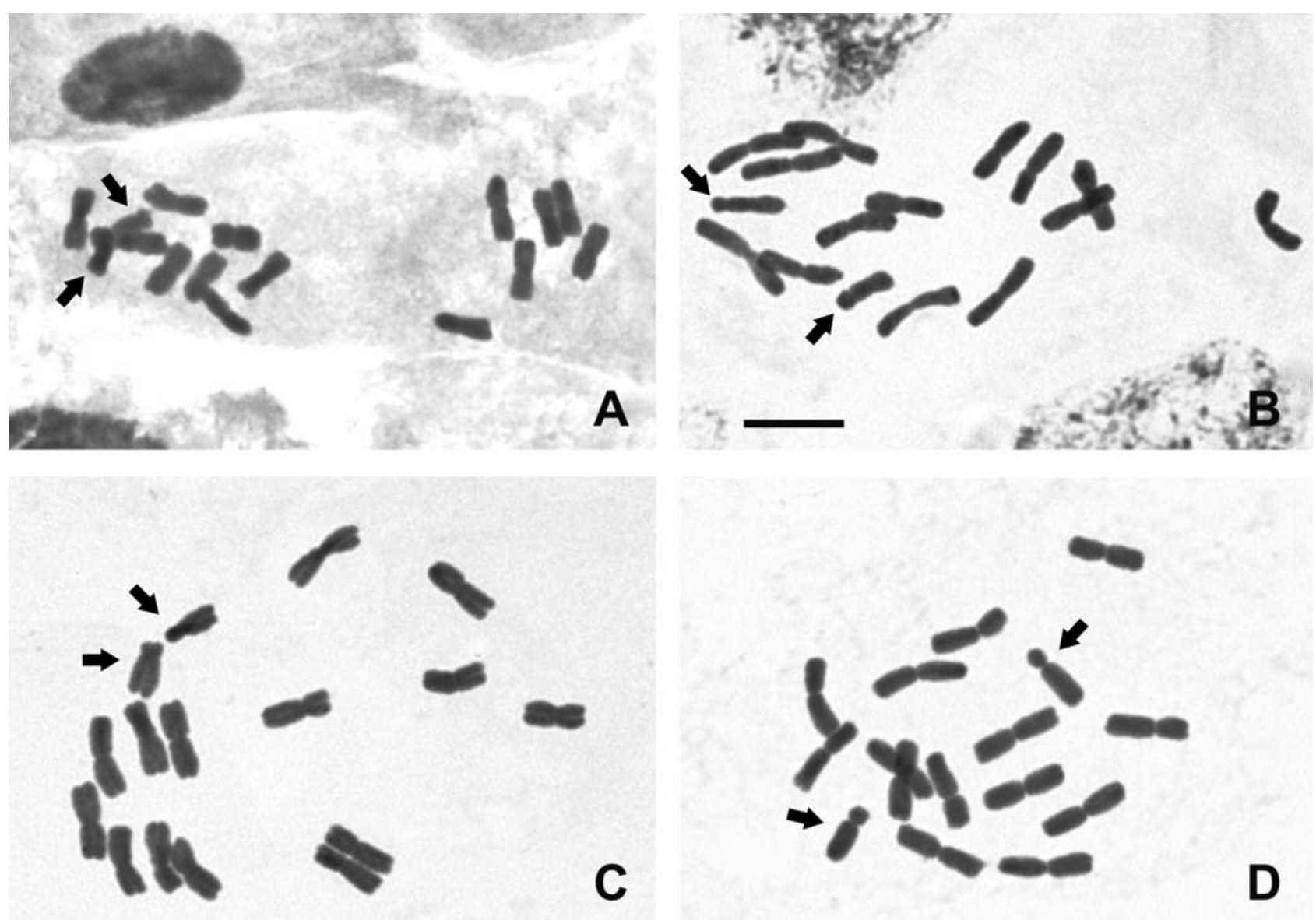

Figure 1 - Conventional staining in Cestrum species $(2 n=16)$ : C. capsulare (A), C. corymbosum (B), C. laevigatum (C) and C. megalophylum (D). Arrows point to submeta-to-acrocentric pair 8 and some chromocenters in partial nuclei of $C$. corymbosum. Bar $=10 \mu \mathrm{m}$.

preferentially in the terminal and subterminal regions. Most of the smaller blocks or dots were observed in the interstitial regions (Figure 2), except for Cestrum capsulare that exhibited a great number of C-DAPI ${ }^{+}$dots located in interstitial and terminal regions (Figure 4A). Cestrum corymbosum showed the largest C-DAPI ${ }^{+}$bands in the interstitial region of the short arm of pairs 1, 2 and 3, and dots in the interstitial regions of pairs 1, 2, 4, 5, 6 and 7 (Figures $2 \mathrm{C}$ and $4 \mathrm{~B}$ ). Cestrum laevigatum presented the smallest number of C-DAPI ${ }^{+}$bands, located mainly in the interstitial regions of the short arms of pairs 1, 4 and 6 . The only paracentromeric band was $\mathrm{C}-\mathrm{CMA}^{+} / \mathrm{DAPI}^{+}$, observed on the long arm of pair 8 (Figures $2 \mathrm{E}$ and $4 \mathrm{C}$ ). Cestrum megalophylum showed pericentromeric C-DAPI ${ }^{+}$blocks on all chromosomes, except for pair 8, which was $\mathrm{C}-\mathrm{CMA}^{+} / \mathrm{DAPI}^{+}$. It is important to point out that pericentromeric $\mathrm{C}-\mathrm{DAPI}{ }^{+}$bands were not strongly evident in all the preparations of C. megalophylum. Larger interstitial C-DAPI ${ }^{+}$bands were found in pairs 3 and 7, besides interstitial dots in pairs 2, 4 and 6 (Figures $2 \mathrm{G}$ and 4D).

$\mathrm{C}-\mathrm{CMA}^{+}$bands were usually present in the terminal regions of the short arms of meta-, submeta- and acrocentric chromosomes. In C. capsulare, besides the terminal blocks on pairs 6 and 8 associated with NORs, some inter- stitial dots were found in subterminal regions, except in pairs 6 and 7. C-CMA ${ }^{+} / \mathrm{DAPI}^{+}$bands were observed in the terminal region of pair 1 and in interstitial positions on the short arms of pair 6 (Figures 2B and 4A). Cestrum corymbosum showed terminal C-CMA ${ }^{+}$blocks on pairs 7 and 8 , in addition to a paracentromeric dot on the long arm of pair 8 (Figures 2D and 4B). In Cestrum laevigatum, $\mathrm{C}-\mathrm{CMA}^{+} / \mathrm{DAPI}^{+}$blocks were observed in the terminal region of pairs 3 and 7 , besides a paracentromeric dot on the

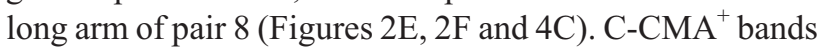
were located in the terminal region of five chromosomes in C. megalophylum, on the short arms of pairs 4 and 7 and of the larger chromosome of the heteromorphic pair 1, and in the paracentromeric region (dot) of the long arms of pair 8 (Figures 2H and 4D). Only the bands observed in pairs 1 and 8 were $\mathrm{C}-\mathrm{CMA}^{+} / \mathrm{DAPI}^{+}$.

All FISH assays with the $45 \mathrm{~S}$ rDNA probe showed four terminal signals, preferentially on the short arms, except for a heteromorphism in C. megalophylum, where five chromosomes hybridized to the probe (Figures 3 and 4). Differences in signal sizes and positions were found. In Cestrum capsulare, hybridization sites were observed on pairs 6 and 8 (Figures $3 \mathrm{~A}$ and 4A), and in C. corymbosum on pairs 7 and 8 (Figures $3 \mathrm{~B}$ and $4 \mathrm{~B}$ ). In both cases, the $45 \mathrm{~S}$ 

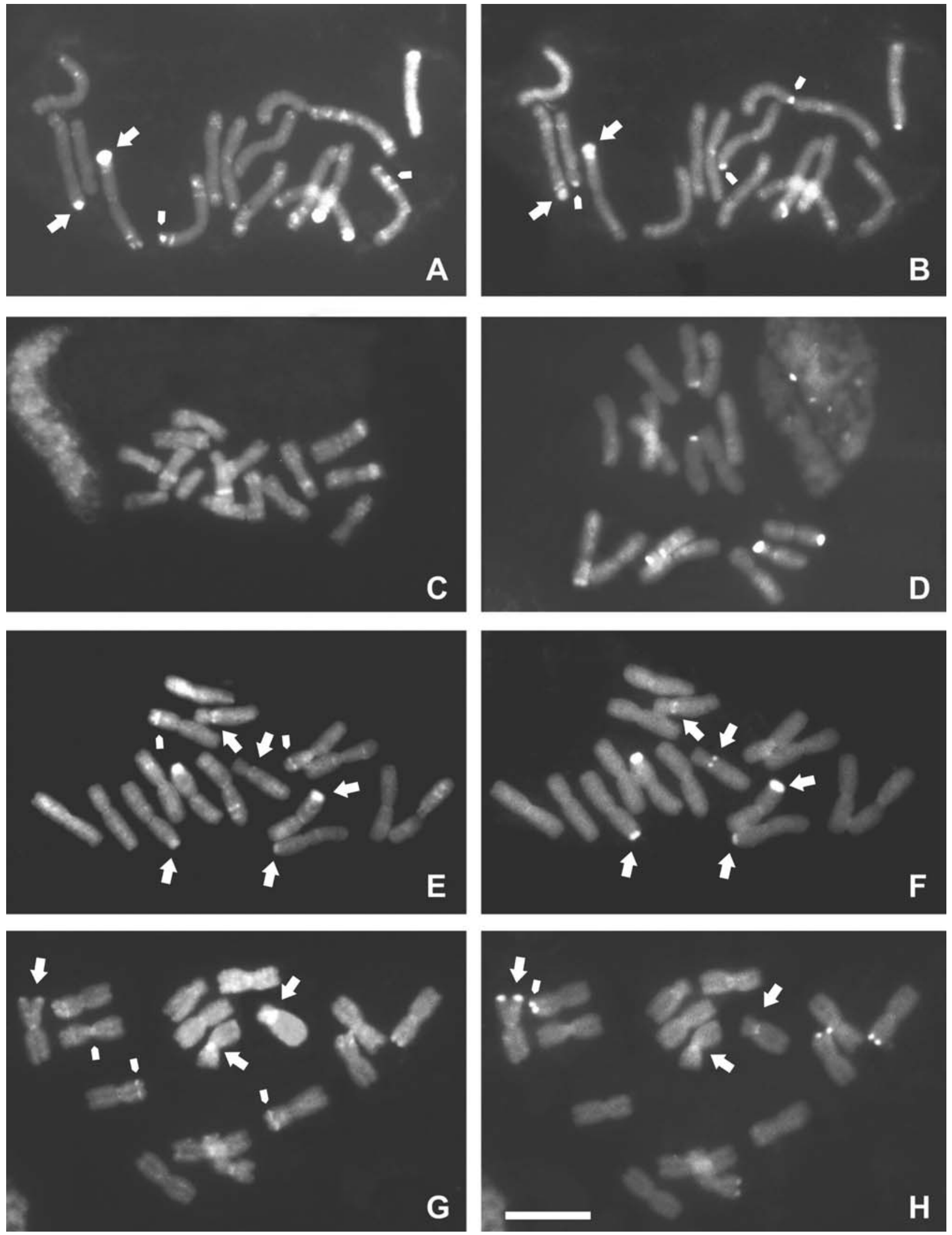

Figure 2 - Chromosome banding with fluorochromes in Cestrum species: C-DAPI banding in C. capsulare (A); C. corymbosum, incomplete metaphase (C); C. laevigatum (E); and C. megalophylum (G). C-CMA banding in C. capsulare (B), C. corymbosum (D), C. laevigatum (F) and C. megalophylum

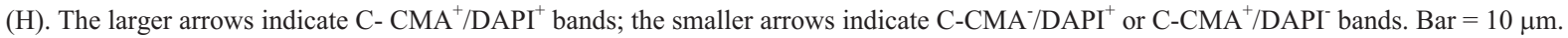


rDNA was associated with GC-rich bands. In $C$. laevigatum, signals were observed on pairs 3 and 7 (Figures $3 \mathrm{C}$ and $4 \mathrm{C}$ ), but associated with $\mathrm{C}-\mathrm{CMA}^{+} / \mathrm{DAPI}^{+}$bands. In C. megalophylum, hybridization signals were observed on pairs 4 and 7, associated with GC-rich bands, besides the larger chromosome of the heteromorphic pair 1, associated with $\mathrm{C}-\mathrm{CMA}^{+} / \mathrm{DAPI}^{+}$bands (Figures $3 \mathrm{D}$ and $4 \mathrm{D}$ ). FISH with the 5S rDNA probe showed hybridization signals always in the proximal region of pair 8 , associated with GC-rich bands in C. corymbosum (Figures $3 \mathrm{~B}$ and 4B) and associated with $\mathrm{C}-\mathrm{CMA}^{+} / \mathrm{DAPI}^{+}$bands in $C$. laevigatum and $C$. megalophylum (Figures $3 \mathrm{C}$ and $4 \mathrm{C}$ and Figures 3D and 4D, respectively). Cestrum capsulare showed a hybridization signal on pair 4 , but also in the paracentromeric region of the largest chromosome (Figures 3A and 4A).

\section{Discussion}

Cytogenetic analysis, performed for the first time in C. capsulare, $C$. corymbosum, $C$. laevigatum and $C$. megalophylum, showed a constant chromosome number ( $2 n=2 x=16)$, as previously described for Cestrum (Berg and Greilhuber, 1992, 1993a, 1993b; Fregonezi et al., 2006). In addition to the numerical stability, other cytogenetic features were also constant, such as the predominance of meta- and submetacentric chromosomes, with pair 8 always being acrocentric, and the reticulate interphase nuclei (Berg and Greilhuber, 1992, 1993a, 1993b; Fregonezi et al., 2006; Las Peñas et al., 2006). Although there was a predominance of metacentrics and two submetacentrics for pair 8 in this study, some arm ratio values were very close to the limit between meta- and submetacentrics and submeta- and acrocentrics as defined by Guerra (1986) (see Figure 4). It is important to emphasize that the apparent constancy of chromosome number and karyotype morphology found in Cestrum was also observed in conventional cytogenetic studies of other Solanaceae, such as the genera Capsicum L. (Pozzobon et al., 2006), Solanum L. (Bernardello and Anderson, 1990) and Lycopersicum Hill (Pillen et al., 1996), all with $2 n=24$.

Our results complement those obtained by Berg and Greilhuber (1992, 1993a, 1993b), Fregonezi et al. (2006) and Las Peñas et al. (2006), pointing out that there are some minor variations in the chromosome types regarding centromere position, chromosome size and karyotype symmetry. Las Peñas et al. (2006) proposed that an increase in genome size is accompanied by a small karyotype asymmetry, common in the tribe Cestreae. According to these authors, Vestia species are the most plesiomorphic within Cestreae, with the most symmetrical karyotypes and the smallest chromosomes. On the other hand, Sessea and Cestrum species are more apomorphic, with more asymmetrical karyotypes and larger chromosomes. Our results partially support the ideas of Las Peñas et al. (2006), once C. capsulare showed the most symmetrical karyotype and
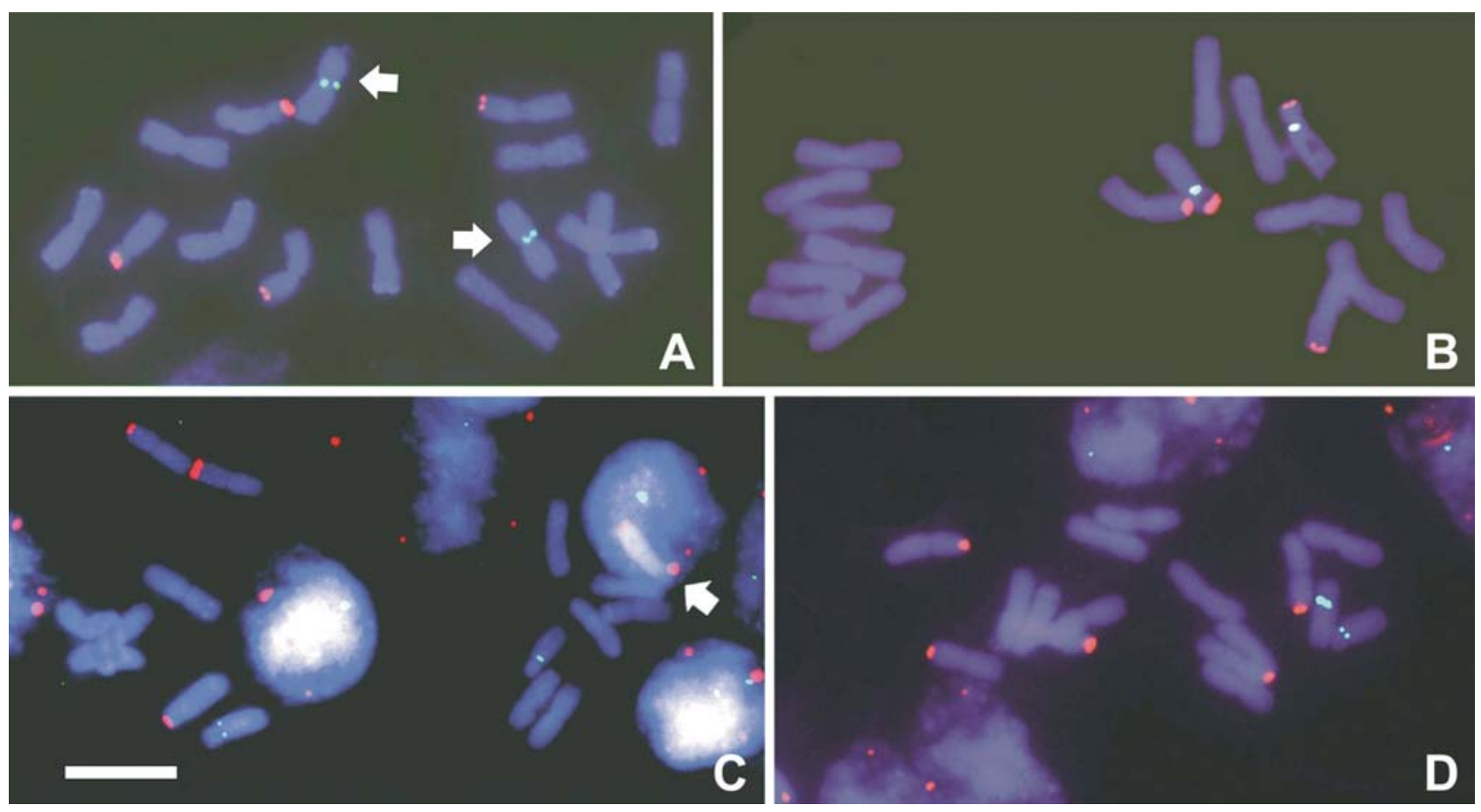

Figure 3 - FISH with the $45 \mathrm{~S}$ rDNA probe detected with anti-digoxigenin-rhodamine (red) and the $5 \mathrm{~S}$ rDNA probe detected with biotin-FITC (green) in Cestrum species ( $2 n=16)$ : (A) Cestrum capsulare, (B) C. corymbosum, and (C) C. laevigatum. Note the four 45S rDNA sites always located in terminal regions and two 5S rDNA sites always in proximal regions of pair 8, except for Cestrum capsulare, where the 5S rDNA signal was observed on the metacentric pair 4 (arrows). In Figure (C), the arrow points to a chromosome containing the $45 \mathrm{~S}$ rDNA site overlapped in the nuclei. (D) $C$. megalophylum showing five terminal signals of $45 \mathrm{~S}$ rDNA and two proximal signals of $5 \mathrm{~S}$ rDNA on pair 8 . Bar $=10 \mu \mathrm{m}$. 

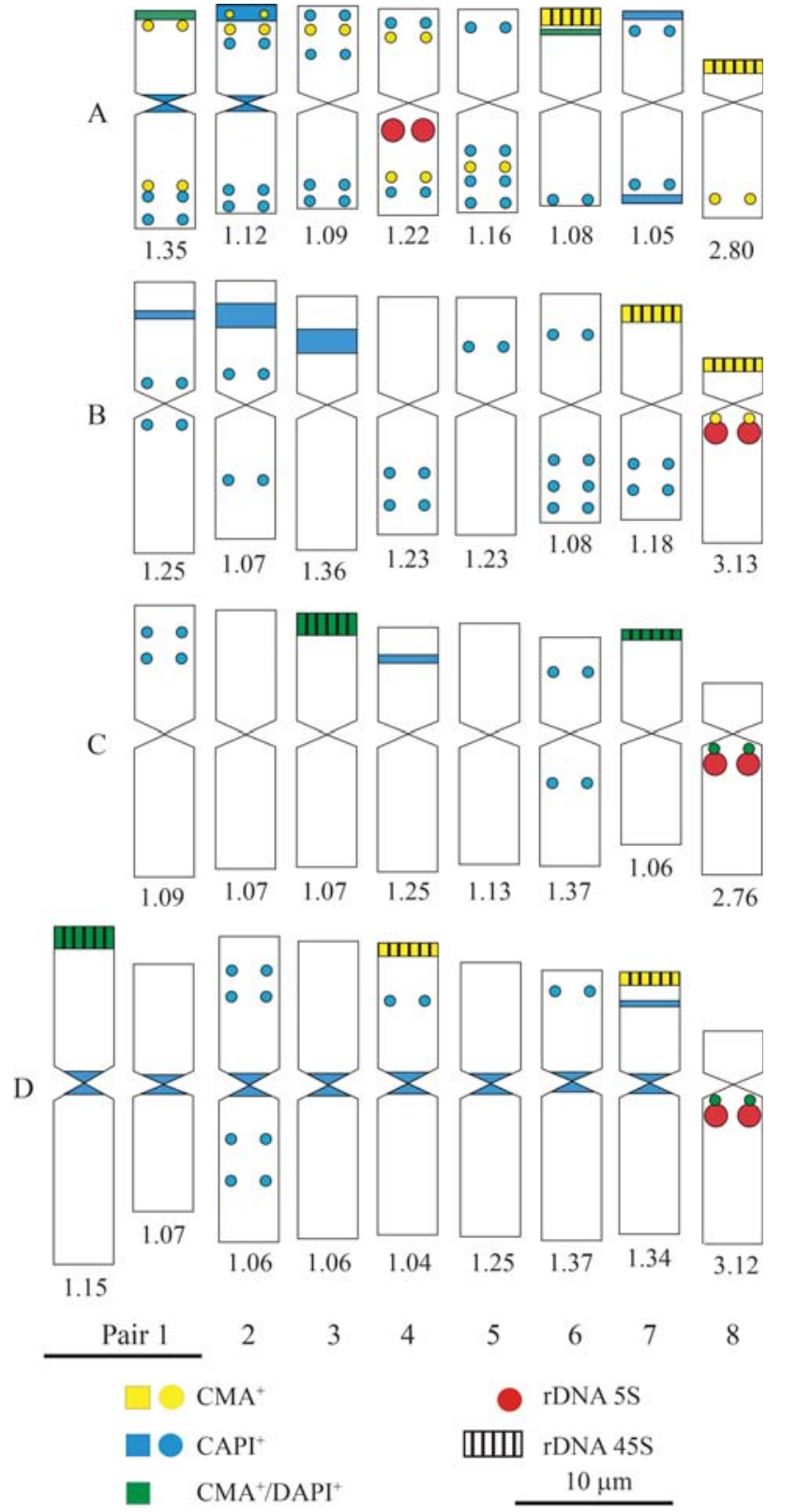

Figure 4 - Idiograms with physical location of repetitive segments in Cestrum capsulare (A), C. corymbosum (B), C. laevigatum (C) and C. megalophylum (D). Numbers below the idiograms correspond to arm ratios, according to Guerra (1986): metacentric (m) with arm ratios (ar) from 1.00 to 1.49 , submetacentric (sm) with ar from 1.50 to 2.99 , acrocentric (a) with $a r>3.0$.

had the smallest haploid set size, while C. megalophylum presented the most asymmetrical karyotype and the largest haploid set size. This difference is sustained by taxonomic data, since $C$. capsulare was once classified into the genus Sessea (Sessea regnellii Taub.) and was later reclassified to Cestrum (Carvalho and Schnoor, 1997). However, chromosome banding (described below) showed that $C$. capsulare accumulated more repetitive DNA than the other three species, which could produce an increase in karyotype differences, including asymmetry.
Chromosome banding showed variation in the type, amount and distribution of heterochromatin among the four Cestrum species studied. However, we also found similarities, mainly with regard to the equilocal/equidistant and non- equilocal/equidistant distribution of bands (see Schweizer and Ehrendorfer, 1976; Schweizer and Loidl, 1987). C-CMA/DAPI banding allowed the identification of chromosomes and karyotypes, and the construction of idiograms, as previously demonstrated by Berg and Greilhuber (1992, 1993a, 1993b) and Fregonezi et al. (2006).

The physical maps defined three "domains" for heterochromatin occurrence in Cestrum. The first one was represented by the largest terminal $\mathrm{C}_{-} \mathrm{CMA}^{+}$and $\mathrm{C}_{-} \mathrm{CMA}^{+} / \mathrm{DAPI}^{+}$bands. The terminal C-CMA ${ }^{+}$blocks were equilocal and equidistant, with interstitial dots on some heterologous chromosomes of $C$. capsulare. The second domain was represented by the largest interstitial/subterminal C-DAPI ${ }^{+}$bands, which are equilocal and equidistant, with C-DAPI ${ }^{+}$dots in C. corymbosum and less frequently in C. laevigatum and C. megalophylum. The third domain was represented by centromeric C-DAPI ${ }^{+}$bands in Cestrum capsulare and C. megalophylum. The occurrence of these "domains" could be explained by the model of Schweizer and Loidl (1987), where different types of heterochromatin could begin preferentially in terminal regions and afterwards "contaminate" the interstitial regions of adjacent non-homologous chromosomes. Similar cases were reported in Gibasis karwinskyana (Roem. \& Schult.) Rohw., Commelinaceae (Kenton, 1991) and some Cestrum species (Berg and Greilhuber, 1992, 1993a, 1993b; Fregonezi et al., 2006). This kind of dispersion was found here in $C$. corymbosum and C. megalophylum, and was previously reported for C. intermedium and C. strigilatum (Fregonezi et al., 2006).

The centromeric heterochromatin dispersion pattern detected by chromosome banding procedures can be considered of little importance in Cestrum, if compared with other plant groups, for example Ophrys L. (Orchidaceae). D'Emerico et al. (2005) studied seven species of Ophrys and found evident centromeric C-bands (Giemsa) in all the chromosomes. Another example of repetitive DNA accumulation in the centromeric regions of plants was published by Valárik et al. (2002). These authors isolated and cloned several repetitive DNA sequences of Musa acuminata L. (bananas) and, except for those associated with NORs, they appeared clustered in the centromeric regions of all chromosomes, as detected by FISH. These lines of evidence endorse the idea that there are specific positions in the chromosomes where arrays of repetitive DNA are accumulated, favored or tolerated. According to Flavell (1986), the selection process against or in favor of repetitive DNA accumulation can occur in differential ways, and it could also explain the different physical maps generated for Cestrum.

FISH with ribosomal probes showed a common pattern of $45 \mathrm{~S}$ rDNA distribution in the four species studied 
here compared to other Cestrum species (Fregonezi et al., 2006), since their hybridization sites were always located in the terminal regions of the chromosomes. These segments were found in different numbers but always in terminal regions, as in other genera of Solanaceae, such as Capsicum (Moscone et al., 1995) and Nicotiana L. (Lim et al., 2000). Cestrum capsulare, C. corymbosum and C. laevigatum showed four $45 \mathrm{~S}$ rDNA sites, whereas $C$. megalophylum exhibited a heteromorphic pair with a terminal

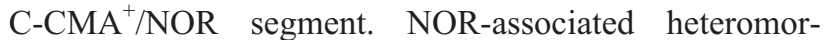
phisms can happen due to non-equal crossing-over, non-reciprocal translocations or deletions. However, our data did not allow us to determine responsible event for these heteromorphisms, as well as if this event was fixed in the population or not, because samples of few individuals were collected in a restricted area. Different numbers of 45S rDNA sites have been described for Cestrum, varying from four to eight (Fregonezi et al., 2006). Thus, events involving the amplification of rDNA repeats or an increase in the number of sites do not seem to affect the adaptive success of Cestrum species. Additionally, it is possible that other events are responsible for the dispersion of $45 \mathrm{~S}$ rDNA repeats. Fregonezi et al. (2007) showed that a representative of the Ty3-gypsy family appears to be associated with NORs of C. intermedium and C. strigilatum, and that this retroelement could be involved in rDNA mobility among Cestrum species. Franz et al. (2000) suggested that in Arabidopsis the various types of transposable elements associated to NOR regions might favor rDNA mobility and affect both the evolution and the expression of rDNA loci.

The location of the 5S rDNA in paracentromeric regions of the long arm of pair 8 in C. corymbosum, $C$. laevigatum and C. megalophylum is in agreement with that described by Fregonezi et al. (2006) for other Cestrum species. Differences were found in Cestrum capsulare, where its chromosome position is the same, but on a different chromosome (pair 4). It is possible that a translocation has moved the $5 \mathrm{~S}$ rDNA segment from pair 8 to pair 4 , since the long arm of pair 8 of C. capsulare decreased in size and, according to measurements, this pair is not acrocentric as in other Cestrum species, but submetacentric. Another karyotype feature that attracted our attention was the differential association of 5S rDNA with heterochromatin. In this regard, we observed three different conditions: (i) lack of association with heterochromatin, as in C. capsulare; (ii) association with $\mathrm{C}_{-} \mathrm{CMA}^{+}$segments, as found in $C$. corymbosum; and (iii) association with $\mathrm{C}_{-} \mathrm{CMA}^{+} / \mathrm{DAPI}^{+}$ segments, as found in C. laevigatum and C. megalophylum. The co-location of 5S rDNA and heterochromatin has already been described for other species. Xu and Earle (1996) showed that in Lycopersicum (Solanaceae) the 5S rDNA was associated with heterochromatic bands, and Cerbah et al. (1998) and Ruas et al. (2005) reported this association in several species of Hypochoeris L. (Asteraceae). The occurrence of paracentromeric 5S rDNA on the long arm of pair
8 is considered conserved in Cestrum, but the discovery in C. capsulare, which had been earlier ascribed to the genus Sessea (S. regnellii), can indicate two possibilities: (i) with the increase in the number of species studied, this location cannot be considered a good chromosome marker for the genus; or (ii) our results may be in contradiction to the junction of the genera Cestrum and Sessea, which was based on the diagnosis of fruit morphology, as proposed by Carvalho and Schnoor (1997). However, when we consider the general cytogenetic features of $C$. capsulare, including large chromosomes, a great number of heterochromatic blocks, equilocal distribution and number and location of $45 \mathrm{~S}$ rDNA, C. capsulare seems to be well bounded.

In conclusion, the physical mapping generated after fluorescent chromosome banding and FISH with $45 \mathrm{~S}$ and 5S rDNA, when compared with the maps generated for other Cestrum species, reinforces the idea that the karyotype changes in Cestrum resulted mainly from a great variation in the occurrence and distribution of different repetitive DNA segments, without major modifications in the karyotype formulae and chromosome size.

\section{Acknowledgments}

The authors thank the Brazilian agencies Fundação Araucária, IAP-SEMA and CNPq for financial support and Prof. Dr. José Marcelo D. Torezan for critical review and suggestions. Dr. A. Leyva provided English editing of the manuscript.

\section{References}

Berg C and Greilhuber J (1992) Cold-sensitive chromosome regions and their relation to constitutive heterochromatin in Cestrum parqui (Solanaceae). Genome 35:921-930.

Berg C and Greilhuber J (1993a) Cold-sensitive chromosome regions and heterochromatin in Cestrum (Solanaceae): $C$. strigilatum, C. fasciculatum and C. elegans. Plant Syst Evol 185:133-151.

Berg C and Greilhuber J (1993b) Cold-sensitive regions and heterochromatin in Cestrum aurantiacum (Solanaceae). Plant Syst Evol 185:259-273.

Bernardello LM and Anderson GJ (1990) Karyotypic studies in Solanum section Basarthrum (Solanaceae). Am J Bot 77:420-431.

Carvalho LAF and Schnoor A (1997) Sessea Carvalho et Schnoor - Nova seção para o gênero Cestrum (Solanaceae). Rodriguésia 46:15-24.

Cerbah M, Coulaud J and Siljak-Yakovlev S (1998) rDNA organization and evolutionary relationship in the genus Hypochaeris (Asteraceae). J Hered 89:312-318.

Cuadrado A and Jouve N (1994) Highly repetitive sequences in B chromosomes of Secale cereale revealed by fluorescence in situ hybridization. Genome 37:709-712.

D'Emerico S, Pignone D, Bartolo G, Pulvirenti S, Terrasi C, Stuto S and Scrugli A (2005) Karyomorphology, heterochromatin patters and evolution in the genus Ophrys (Orchidaceae). Bot J Lin Soc 148:87-99. 
Flavell RB (1986) Repetitive DNA and chromosome evolution in plants. Phil Trans R Soc Lond 312:227-242.

Franz PF, Armstrong S, de Jong H, Parnell LD, Drunen CV, Dean C, Zabel P, Bisseling T and Jones G (2000) Integrated cytogenetic map of chromosome arm $4 \mathrm{~S}$ of A. thaliana: Structural organization of heterochromatic knob and centromere region. Cell 100:367-376.

Fregonezi JN, Fernandes T, Torezan JMD, Vieira AOS and Vanzela ALL (2006) Karyotype differentiation of four Cestrum species (Solanaceae) based on physical mapping of repetitive DNA. Genet Mol Biol 29:97-104.

Fregonezi JN, Vilas-Boas LA, Fungaro MHP, Gaeta ML and Vanzela ALL (2007) Distribution of a Ty3/gypsy-like retroelement on the A and B-chromosomes of Cestrum strigilatum Ruiz \& Pav. and Cestrum intermedium Sendtn. (Solanaceae). Genet Mol Biol 30:599-604.

Gerlach WL and Bedbrook JR (1979) Cloning characterization of ribosomal RNA genes from wheat and barley. Nucleic Acids Res 7:1869-1885.

Gerlach WL and Dyer TA (1980) Sequence organization of the repeating units in the nucleus of wheat which contain $5 \mathrm{~S}$ rDNA genes. Nucleic Acids Res 8:4851-4865.

Guerra M (1986) Reviewing the chromosome nomenclature of Levan et al. Rev Bras Genet 9:741-743.

Heslop-Harrison JS, Schwarzacher T, Anamthawat-Jonsson K, Leitch AR, Shi M and Leitch IJ (1991) In situ hybridization with automated chromosome denaturation. Technique 3:106-109.

Hunziker AT (1979) South American Solanaceae, a synoptic survey. In: Hawkes JG, Lester RN and Skelding AD (eds) The Biology and Taxonomy of the Solanaceae. 7th edition. Linnean Society Symposium Series. Academic Press, New York, pp 49-86.

Hunziker AT (2001) Genera Solanacearum: The Genera of Solanaceae Illustrated, Arranged According to a New System. Gantner Verlag K.-G., Liechtenstein, 500 pp.

The Genera of Solanaceae. A.R.G. Gantner Verlag K.-G., Liechtenstein, $500 \mathrm{pp}$.

Judd WS, Campbell CS, Kellogg EA and Stevens PF (1999) Plant Systematics: A Phylogenetic Approach. Sinauer Associates, Sunderland, $464 \mathrm{pp}$.

Kenton A (1991) Heterochromatin accumulation, disposition and diversity in Gibasis karwinskyana (Commelinaceae). Chromosoma 100:467-478.

Las Peñas ML, Chiarini FE, Bernardello G and Benítez de Rojas C (2006) Karyotypes of some species of Cestrum, Sessea and Vestia (tribe Cestreae, Solanaceae). Caryologia 59:131-137.
Lim KY, Matyasek R, Lichtenstein CP and Leitch AR (2000) Molecular cytogenetic analyses and phylogenetic studies in the Nicotiana section Tomentosae. Chromosoma 109:245-258.

Moscone EA, Loidl J, Ehrendorfer F and Hunziker AT (1995) Analysis of active nucleolus organizing regions in Capsicum (Solanaceae) by silver staining. Am J Bot 82:276-287.

Pillen K, Pineda O, Lewis CB and Tanksley SD (1996) Status of genome mapping tools in the taxon Solanaceae. In: Paterson $\mathrm{AH}$ and Landes RG (eds). Genome Mapping in Plants. Landes Company, Texas, pp 281-308.

Pozzobon MT, Schifino-Wittmann MT and Bianchetti LB (2006) Chromosome numbers in wild and semidomesticated Brazilian Capsicum L. (Solanaceae) species: Do $x=12$ and $x=$ represent two evolutionary lines? Bot J Lin Soc 151:259-269.

Ruas CF, Vanzela ALL, Santos MO, Fregonezi JN, Ruas PM, Matzenbacher NI and Aguiar-Perecin MLR (2005) Chromosomal organization and phylogenetic relationships in Hypochaeris species (Asteraceae) from Brazil. Genet Mol Biol 28:129-139.

Schwarzacher TP, Ambros P and Schweizer D (1980) Application of Giemsa banding to orchid karyotype analysis. Plant Syst Evol 134:293-297.

Schweizer D and Ehrendorfer FW (1976) Giemsa banded karyotypes, systematics, and evolution in Anacyclus (AsteraceaeAnthemideae). Plant Syst Evol 126:107-148.

Schweizer D and Loidl J (1987) A model for heterochromatin dispersion and the evolution of C-banded patterns. Chrom Today 9:61-74.

Sykorová E, Lim KY, Chase MW, Knapp S, Leitch IJ, Leitch AR and Fajkus J (2003a) The absence of Arabidopsis-type telomeres in Cestrum and closely related genera Vestia and Sessea (Solanaceae); first evidence from eudicots. Plant J 34:283-291.

Sykorová E, Lim KY, Fakijus J and Leitch AR (2003b) The signature of the Cestrum genome suggests an evolutionary response to the loss of (TTTAGGG) n $_{\mathrm{n}}$ telomeres. Chromosoma 112:164-172.

Valárik M, Simková H, Hribová E, Safár J, Dolezevolá M and Dolzel J (2002) Isolation, characterization and chromosome localization of repetitive DNA sequences in bananas (Musa spp.). Chromosome Res.10:89-100.

$\mathrm{Xu} J$ and Earle ED (1996) High-resolution physical mapping of $45 \mathrm{~S}(5.8 \mathrm{~S}, 18 \mathrm{~S}$ and $25 \mathrm{~S})$ rDNA gene loci in the tomato genome using a combination of karyotyping and FISH of pachytene chromosomes. Chromosoma 104:545-550.

Associate Editor: Marcelo Guerra

License information: This is an open-access article distributed under the terms of the Creative Commons Attribution License, which permits unrestricted use, distribution, and reproduction in any medium, provided the original work is properly cited. 